\title{
SISTEMAS MIGRATORIOS EN EL NORTE DE ÁFRICA: EVOLUCIÓN, TRANSFORMACIONESY VÍNCULOS CON EL DESARROLLO
}

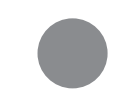

HEIN DE HAAS

TRADUCCIÓN DE LUIS RODOLFO MORÁN QUIROZ

\begin{abstract}
RESUmen. Este artículo analiza, primero, cómo la evolución y transformación de los sistemas migratorios de África del Norte ha sido una parte integral de un proceso más general de cambio político y económico. Posteriormente, el alcance con el que las políticas pueden mejorar el impacto en el desarrollo de la migración, utilizando, como ejemplo, el análisis del caso de Marruecos, el país con más altos índices de migración de la región. Más de 3 millones de personas de origen marroquí (de 30 millones de marroquíes) viven fuera de su país, la mayor parte en Europa. Desde la década de los 60's, el estado de Marruecos ha estimulado la migración por razones económicas y políticas, al mismo tiempo que trataba de mantener un fuerte control de «sus» emigrantes. Sin embargo, debido al temor que causaba una baja en el flujo de remesas, se dio un cambio notable después de 1989. Al tiempo que definía políticas para facilitar el flujo de remesas y de visitas vacacionales, el Estado marroquí adoptó actitudes positivas hacia el activismo cívico de los migrantes, su integración y doble ciudadanía. El gran incremento en las remesas (por arriba de cinco mil millones en 2006) y en las visitas vacacionales de los emigrados sugiere que estas políticas han sido parcialmente exitosas. Sin embargo, estas políticas podrían funcionar solamente debido a la estabilidad macro-económica y a la continuada emigración, así como a que las mismas formaron parte de un proceso más general de liberalización de la sociedad de Marruecos.
\end{abstract}

Palabras ClaVE. Migración Internacional, desarrollo, remesas políticas, África del Norte.

Aвstract. The paper first analyses how the evolution and transformation of North African migration systems has been an integral part of more general processes of political and economic change. Subsequently, the extent to which policies can enhance the development impact of migration is assessed by analysing the case of Morocco, the region's leading emigration country. Over 3 million people of Moroccan descent (out of 30 million Moroccans) live abroad, mainly in Europe. Since the 1960's, the Moroccan state has stimulated migration for economic and political reasons, while simultaneously trying to maintain a tight control on «its» emigrants. However, fearing remittance decline, a remarkable shift occurred after 1989. Along with policies to facilitate holiday visits and remittances, the Moroccan state adopted positive attitudes towards migrants' transnational civic activism, integration and double citizenship. Huge increases in remittances (well over $\$ 5$ billion in 2006) and holiday visits suggest that these policies have been partially successful. However, these policies could only work because of macro-economic stability and continuing emigration, and because they were part a more general process of liberalisation of Moroccan society.

KEYwORDs. International migration, development, remittances, policies, North Africa. 


\section{INTRODUCCIÓN}

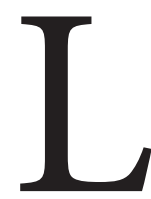

as transformaciones políticas, sociales y económicas verificadas en África, ${ }^{1}$ en las últimas décadas, resultarían incomprensibles de no considerarse el papel de los movimientos migratorios en el continente. Por su vecindad con los países desarrollados de la Unión Europa (UE) y el Consejo de Cooperación del Golfo (CCG), el norte de África se ha convertido en una de las principales «fronteras de mano de obra» (Skeldon, 1997). La migración a gran escala, además de responder a la demanda laboral de los países de la UE y el CCG, afecta las bases del desarrollo social y económico de la región.

Se estima que viven en el extranjero más de 8 millones de personas provenientes del norte de África, de los cuales, 4.7 millones se ubican en Europa y 2.4 en países petroleros árabes. Asimismo, el norte de África ha generado una significativa migración laboral dentro de la región, en particular hacia Libia, también un país petrolero. En la última década, el norte de África parece haber entrado en una suerte de transición migratoria, cuyos rasgos más sobresalientes, además de la continua emigración, son la creciente inmigración procedente de los países subsaharianos y el papel norafricano como zona de tránsito para migrantes subsaharianos e incluso asiáticos que desean ingresar a Europa.

La ascendente migración norafricana ha tensionado las relaciones con los países europeos. Especialmente, la UE ha intentado «externalizar» sus políticas de inmigración restrictivas, al presionar a los gobiernos norafricanos para que adopten leyes y regulaciones inmigratorias restrictivas e intensifiquen los controles fronterizos. La creación de una zona de seguridad forma parte de los acuerdos de asociación que ha firmado la UE con todos los países del norte de África, a excepción de Libia, con la intención de establecer una zona de libre comercio, que se supone promueve un desarrollo que reducirá las migraciones en los países norafricanos y en países mediterráneos con tradición migratoria.

No obstante, ante el incumplimiento del objetivo que pretende reducir el flujo migratorio, entre los países europeos emerge el interés por los efectos potencialmente positivos de la migración, las remesas así como el desarrollo social y económico en los países de origen de los migrantes. Los países receptores de inmigrantes suelen percibir el desarrollo impulsado por la migración como una forma de disipar presiones migratorias no deseadas. Recientemente se han cifrado fuertes expectativas en la migración temporal, según una estrategia de «ganar-ganar» que reconcilia tanto los intereses de los migrantes como los de los países de origen y destino (Ruhs, 2005; para reseñas críticas, véase Castles, 2006; De Haas, 2006a).

En este punto específico, puede ser ilustrativo estudiar la experiencia norafricana.

\footnotetext{
${ }^{1}$ Limitaremos nuestro análisis a los países del norte de África con costas en el Mar Mediterráneo: Marruecos, Argelia, Túnez, Libia y Egipto. No obstante, debe hacerse notar que la cortante distinción, entre el Norte de África y África sub-Sahariana, no sólo es históricamente incorrecta por dejar de lado el hecho que el Sahara, por sí mismo, es una enorme zona de transición entre estas dos nociones sub-continentales, sino que también ello se ve contradicho por una importante migración que atraviesa el Sahara.
} 
En primer lugar, para los gobiernos de los países de origen situados en el norte de África, el tema «migración y desarrollo» no es una novedad, ya que la migración ha sido parte integral de su estrategia nacional de desarrollo desde hace décadas. En segundo lugar, las anteriores políticas promovidas por los países europeos y el CCG, para estimular la migración temporal y de retorno, suelen ignorarse en el debate acerca de las nuevas propuestas para estimular la migración temporal desde la región.

La migración es moldeada por, y a la vez ayuda a moldear, procesos más amplios de transformación. Por ello, el propósito de este trabajo es comprender la evolución del sistema migratorio norafricano entre 1945 y 2005 así como de qué manera, ese proceso, está relacionado recíprocamente con procesos más amplios de cambios sociales, políticos y económicos en el norte de África, Europa, Medio Oriente y África subsahariana. Al centrarse en Marruecos, el más importante país de emigración, este trabajo también aborda hasta qué punto los gobiernos de los países de origen han sido capaces de potenciar el impacto de la migración en el desarrollo.

\section{SISTEMA Y TRANSICIÓN MIGRATORIOS}

Para nuestros propósitos analíticos, resulta útil relacionar la experiencia migratoria específica del norte de África con dos conceptos teóricos centrales: sistema migratorio y transición migratoria. Mabogunje (1970), fundador de su teoría, definía el sistema migratorio como un conjunto de espacios vinculados por flujos y contraflujos de personas, bienes, servicios e información, que tienden a facilitar intercambios posteriores, incluida la migración. En tanto que Mabogunje se centraba en la migración rural-urbana del continente africano, Portes y Böröcz (1987) y Kritz et al. (1992) extienden este razonamiento a la migración internacional. Los sistemas de migración internacional consisten en países - o lugares dentro de diferentes países - que intercambian cantidades relativamente considerables de migrantes, también caracterizados por mecanismos de retroalimentación que conectan el traslado de personas entre países y regiones, incluso ciudades, con flujos concomitantes de bienes, capitales (remesas), ideas, representaciones e información (Fawcett, 1989; Gurak y Caces, 1992). El principal supuesto de la teoría del sistema migratorio es que la migración altera las condiciones sociales, culturales, económicas e institucionales, en los dos extremos, receptor y de origen, es decir, todo el espacio de desarrollo dentro del cual operan los procesos migratorios.

La transición migratoria es la noción de que las sociedades y países, paralelamente a la reestructuración económica y las transiciones sociales y demográficas concomitantes, siguen una secuencia de emigración creciente, la coexistencia de emigración e inmigración crecientes hasta, eventualmente, convertirse en países de inmigración neta (Zelinsky, 1971; Skeldon, 1997). Ello se vincula con la noción de joroba migratoria planteada por Martin (1993) así como Martin y Taylor (1996), según la cual, un incremento temporal de la migración — una joroba migratoria - forma parte del proceso de desarrollo económico, dado que es necesario un cierto umbral de riqueza que permita a la gente asumir los costos y riesgos de migrar. 
Factores como los ingresos crecientes, el desarrollo de infraestructura de transporte y comunicaciones, un mejor acceso a la educación y la información, así como los procesos de cambio social y cultural pueden brindar, a la gente, las capacidades y aspiraciones necesarias para migrar: en un principio, la migración es predominantemente interna y en etapas posteriores, cada vez más, tiende a ser internacional (De Haas, 2005). A largo plazo, después de que se haya dado un crecimiento sostenido y el diferencial de oportunidades se haya reducido frente a los países de destino, la tendencia es que la emigración disminuya y los países se transformen, de generadores netos de emigración a receptores de inmigración neta. En el siglo xIX y la primera mitad del siglo xx, la mayoría de los países de Europa occidental pasaron por esa transición (Massey, 1991; Hatton y Williamson, 1998). En las últimas décadas, países como España, Italia, Grecia e Irlanda, en Europa, y Malasia, Taiwán y Corea, en Asia, completaron esa transición migratoria. Con base en la persistente expansión del sistema migratorio europeo en sentido amplio, la pregunta que se plantea es si el norte de África también pasará por transiciones migratorias similares en un futuro cercano.

\section{EVOLUCIÓN DEL SISTEMA MIGRATORIO DEL NORTE DE ÁFRICA}

\section{La migración colonial y postcolonial}

La historia demográfica previa a la colonización del norte de África se caracterizó por patrones cambiantes del establecimiento humano. Los grupos nómadas o seminómadas (trashumantes) recorrían grandes distancias con su ganado entre los pastizales de verano e invierno. Los frecuentes conflictos entre los grupos tribales, a causa de los recursos naturales y el control de las rutas de comercio, estaban asociados con el desarraigo, traslado y reasentamiento de la gente.

En todos los países del norte de África, la modernización y la intrusión colonial, ocurrida a mediados del siglo xIX, desencadenaron procesos de urbanización y una sustancial migración de las zonas rurales a las urbanas. No obstante, sólo en el Magreb ${ }^{2}$ «francés» el colonialismo estuvo asociado con un movimiento internacional sustancial, en contraste con Libia y Egipto. La impronta francesa fue particularmente marcada en Argelia, colonizada en 1830 como parte de Francia. Los protectorados franceses en Túnez y Marruecos se establecieron formalmente en 1881 y 1912, respectivamente. El reclutamiento de mano de obra en el Magreb comenzó durante la Primera Guerra Mundial, cuando una marcada carencia de fuerza de trabajo, en Francia, desencadenó el reclutamiento activo de decenas de miles de hombres para el ejército, la industria y la minería (Muus, 1995: 198). En la Segunda Guerra Mundial, la escasez de mano de

\footnotetext{
2 Aunque también Mauritania y Libia son parte del Itihad al Maghreb al 'Arabi, o la Unión Árabe del Magreb, creada en 1989, utilizamos la delimitación más convencional en sus tres principales estados.
} 
obra desencadenó, nuevamente, el reclutamiento de trabajadores y soldados magrebíes (De Haas, 2007).

En Egipto, bajo control británico en 1882, las políticas de modernización fueron puestas en práctica en la segunda mitad del siglo XIX y, simbólicamente, se cristalizaron con la inauguración del Canal de Suez en 1869, e intensificaron los patrones tradicionales de migración interna hacia El Cairo y, en menor medida, hacia Alejandría y la zona del Canal de Suez. Hasta los años cincuenta, pocos egipcios, a excepción de algunos estudiantes, emigraban al extranjero y, de hecho, una mayor cantidad de extranjeros, provenientes de los países árabes y otros más, emigraron hacia Egipto (Sell, 1988; Zohry y Harrell-Bond, 2003).

Entre la década de los cincuenta y 1973, dependiendo de su posición política, los intentos de los gobiernos de África septentrional por impedir o desviar la emigración han influido, de manera fundamental, en los patrones migratorios. En una notable inversión de la actual situación, se trató de una época en que los gobiernos de los países de origen impusieron más restricciones que los países receptores, por medio de políticas selectivas de concesión de pasaportes o de requisitos para visas de salida.

Egipto recuperó su independencia en 1953 y después de la crisis de Suez, en 1956, el presidente Nasser salió de la guerra como un héroe árabe, lo que reforzó la posición de Egipto como líder del mundo árabe. A excepción de las políticas de los años sesenta para promover la educación de los estudiantes egipcios en el extranjero, los gobiernos egipcios desanimaron activamente la emigración de mano de obra, principalmente por medio de los requisitos de las «visas de salida» (Choucri, 1977; Sell, 1988). Dentro del régimen socialista de Nasser, la migración se veía como un factor que ponía en peligro el desarrollo nacional debido a la «fuga de cerebros».

Mientras tanto, la migración del Magreb a Francia continuó aún después del final de la Segunda Guerra Mundial. Ya en 1945, la cantidad de trabajadores argelinos y sus familias en Francia alcanzaba cerca de 350,000. ${ }^{3}$ Una vez que Marruecos y Túnez se independizan de Francia, en 1956, persisten en gran parte los patrones «coloniales» de migración. Debido a que Francia dejó de reclutar trabajadores argelinos durante la guerra de independencia de ese país (1954-1962), la migración de los trabajadores industriales y mineros de Marruecos se vio aumentada (De Haas, 2007). No obstante, la migración argelina continuó, como consecuencia de los levantamientos causados por la guerra de 1954-62, pero también por la demanda de trabajadores en la economía francesa en rápida expansión (Collyer, 2003). En 1962, más de un millón de colons y harkis (argelinos que prestaron servicio en el ejército francés en la guerra de independencia) salieron de Argelia después de que el Frente de Liberación Nacional (FLN) logró sacar a los franceses. Entre 1946 y 1968, seis años después de la independencia argelina, a quienes provenían de ese país se les permitió circular libremente entre Argelia y Francia (Collyer, 2003).

\footnotetext{
${ }^{3}$ Fuente: http://www.country-data.com/cgi-bin/query/r-361.html (consultada el 16 de mayo de 2006).
} 
El auge de los trabajadores huéspedes (1963-1972)

La migración postcolonial fue bastante modesta en comparación con la década posterior a 1962, durante la cual el Magreb se integró, firmemente, en el sistema migratorio euro-mediterráneo. Durante este periodo, los países magrebíes experimentaron el mayor auge en la migración laboral de mano de obra hacia Europa. Marruecos y, en menor medida, Túnez continuaron con la diversificación de sus destinos migratorios más allá de Francia. El rápido crecimiento económico posterior a la guerra, en el noroeste europeo, generó cada vez mayor escasez de mano de obra en sectores como la industria, la minería, la construcción de vivienda y la agricultura. Ello desencadenó una creciente emigración de «trabajadores huéspedes» desde los países más pobres en torno al Mediterráneo. Hasta principios de los años sesenta, la mayoría era reclutada en los países del sur de Europa. Cuando se estancó esa migración, la atención estuvo centrada en los países del sur del Mediterráneo. Maruecos y Túnez firmaron acuerdos formales para el reclutamiento de trabajadores con Francia, Alemania, Bélgica y Holanda (véase tabla 1). En 1968, los gobiernos argelino y francés acordaron una cuota de 350,000 migrantes por año, que luego se redujo a 25,000, en 1971 (Fargues, 2004). La migración se disparó particularmente a partir de 1967, para alcanzar su clímax en 1972 (De Haas, 2007).

TABLA 1

Años en que se firmaron los acuerdos de reclutamiento de mano de obra con Marruecos y Túnez

\begin{tabular}{|c|c|c|c|c|c|}
\hline & FRANCIA & $\begin{array}{c}\text { ALEMANIA } \\
\text { OCCIDENTAL }\end{array}$ & BÉLGICA & HOLANDA & LIBIA \\
\hline Marruecos & 1963 & 1963 & 1964 & 1969 & NA \\
\hline Túnez & 1963 & 1965 & 1969 & 1970 & 1971 \\
\hline
\end{tabular}

Fuentes: Baduel (1980), De Haas (2007).

La influencia del reclutamiento formal por agencias especializadas sólo fue importante en los años iniciales de la migración de mano de obra, y «estableció el escenario» de la posterior migración en cadena. Ya en los años sesenta, el establecimiento espontáneo y el reclutamiento informal, por mediación de las redes de migrantes por las compañías, se tornó numéricamente mucho más importante. Los obstáculos administrativos, las listas de espera y la corrupción que les acompañaba incitaron, a la gente, a evitar estos factores y a migrar como turistas y, después, quedarse más allá del tiempo que tenían autorizado (Reniers, 1999: 683). La mayoría de los migrantes logró obtener papeles, para la residencia permanente, por medio de una serie de campañas de legalización en Holanda (1975), en Bélgica (1975) y en Francia (1981-1982) (Muus, 1995: 199).

Mientras que la migración argelina siguió orientada sobre todo a Francia, Alemania se convirtió en el segundo destino en importancia para los tunecinos, mientras que Bélgica y Holanda se desarrollaron como destinos secundarios para la migración ma- 
rroquí. Túnez y, en particular, Marruecos estimularon políticas fuertemente orientadas a favorecer la migración, con la expectativa de que sus países se beneficiarían en buena parte de la experiencia, entrenamiento y recursos financieros de los migrantes, de los que se esperaba que retornaran.

\section{El punto de inflexión \\ de la crisis petrolera de 1973}

El impacto de la guerra de octubre de 1973, entre árabes e israelíes, la crisis petrolera y la consiguiente recesión económica en Europa occidental reconformarían, dramáticamente, y expandirían el panorama migratorio del norte de África. Para la migración magrebí-europea, anunciaba el fin de la «etapa de reclutamiento» y el inicio de políticas de inmigración cada vez más restrictivas por parte de los gobiernos europeos, una tendencia que persistiría hasta nuestros días. Muy por el contrario, para los países árabes petroleros, los eventos de 1973 marcarían el comienzo del reclutamiento masivo de mano de obra.

El cambio político en Egipto y un crecimiento económico sin precedentes en los países del Golfo que producían petróleo, además de Libia, coincidieron para causar una emigración sin precedentes desde Egipto y, en mucho menor grado, desde los países del Magreb hacia los pujantes países árabes. El embargo petrolero de 1973, en contra de Estados Unidos y de varios de sus aliados occidentales (la «crisis petrolera»), condujo a que se cuadruplicaran los precios del petróleo. El colofón lo constituyeron ambiciosos programas de desarrollo en los países árabes productores de petróleo, lo que condujo a un importante incremento en la demanda de trabajadores. Esto afectó particularmente a Egipto, en donde la cifra registrada de emigrantes se incrementó de 70,000, en 1970, a 1.4 millones, en 1976, y a 2.3 millones, en 1986 (Zohry y Harrell-Bond, 2003: 27, 31).

Esto coincidió con un giro en las políticas migratorias de Egipto, desde la llegada de Sadat al poder en 1970. La infitah de Sadat, o las políticas de puertas abiertas implicaron una reorientación de la Unión Soviética hacia Estados Unidos y el movimiento de la economía egipcia, de la centralización hacia la liberalización y creciente apertura a la inversión extranjera. La migración temporal comenzó a ser vista como un medio para paliar las presiones demográficas y estimular el crecimiento económico. En 1971 se retiraron todas las barreras legales a la migración, al mismo tiempo que se permitió que emigraran los trabajadores del gobierno mientras conservaban el derecho a regresar a sus empleos (OIM, 2005). ${ }^{4}$ Mientras que esta política de puertas abiertas y la liberalización removía las limitaciones estatales y estimulaban el individualismo y los deseos de consumo, muchos

\footnotetext{
${ }^{4}$ Las restricciones a la migración de mano de obra ya habían sido relativamente aminoradas tras la Guerra de los Seis Días, en 1967, y del posterior declive económico, lo que anunció el comienzo de una emigración de mayor duración, al tiempo que los estudiantes en el extranjero tendían a permanecer fuera del país hasta graduarse (Zohry y Harrell-Bond, 2003).
} 
también las vieron como medidas que aumentaban la desigualdad en la sociedad egipcia. Encima de todo ello se acumulaba la «notable reversión de las condiciones económicas relativas» (Sell, 1988:93) entre Egipto y sus vecinos árabes de oriente y occidente.

La mayoría de los migrantes se dirigían a Arabia Saudita, aunque todos los demás países árabes petroleros recibieron su porción de migrantes egipcios. Tanto los trabajadores capacitados como los no capacitados migraron a los países árabes petroleros, aun cuando los trabajadores más calificados preferían los países del Consejo de Cooperación del Golfo (Bahrein, Kuwait, Omán, Qatar, Arabia Saudita y los Emiratos Árabes Unidos). Como proveedor crucial de capacitación específica (como en las áreas de enfermería y docencia) para estos mercados de trabajo, algunos académicos consideran que las políticas educativas en Egipto fueron parte integral de su política de emigración (Fargues, 2004: 1360). Irak, en particular, se convirtió en un destino popular para los migrantes no calificados, por sus políticas liberales de inmigración dirigidas a los otros países árabes y por su necesidad de mano de obra extranjera como consecuencia de la guerra de 1980-1988 en contra de Irán.

La demanda en el extranjero, por mano de obra egipcia, alcanzó su máximo en 1983, cuando se calcula que 3.3 millones de egipcios trabajaban en el extranjero. Después de 1983, la guerra entre Irán e Irak, la caída de los precios del petróleo, la disminución en la demanda de trabajadores de la construcción, la inmigración de mano de obra más barata proveniente de Asia y del sur de dicho continente, así como la política de reemplazar la mano de obra extranjera con nacionales, causaría una caída relativa en la demanda de trabajadores egipcios y de otros países árabes en los países del cCG. Ello coincidiría con una considerable migración de retorno (Zohry y Harrell-Bond, 2003: 27-31).

La crisis petrolera también generó las condiciones para el surgimiento de un nuevo polo migratorio dentro de África septentrional. Cuando Libia se independizó de Italia, en 1951, el país contaba con una pequeña y empobrecida población. El descubrimiento de considerables reservas petroleras, en 1959, cambiaría radicalmente esta situación. Desde principios de los sesenta, la industria petrolera comenzó a dominar la economía y, rápidamente, los ingresos petroleros permitieron que después de 1973, el nuevo líder de la línea de Nasser, Al-Kadafi, lanzara ambiciosos programas de desarrollo social y económico. Como en los países del Golfo, la demanda subsiguiente de mano de obra no podía satisfacerse localmente, lo que desencadenó una importante migración, principalmente de migrantes temporales. Los egipcios han constituido la nacionalidad con mayor presencia en Libia y han trabajado predominantemente en la agricultura y la educación (Hamood, 2006: 17).

El auge económico en los países árabes petroleros también generó una significativa migración desde Túnez y Marruecos. Por razones geográficas y políticas, esta migración estuvo orientada predominantemente hacia Libia y consistió, principalmente, en migrantes con escasa o nula capacitación que permanecían por periodos relativamente cortos. La migración «temporal» de mayor duración de trabajadores calificados hacia los países del Golfo, como la generada desde Egipto, se conservó en cifras relativamente reducidas.

La Argelia socialista, un país petrolero más modesto, se benefició también del aumento repentino de los precios del petróleo en 1973 (Collyer, 2003). Al mismo tiem- 
po que Egipto abandonaba sus políticas restrictivas, Argelia denunciaba la emigración como una forma de dependencia postcolonial (Fargues, 2004:1360) y, formalmente, suspendió toda migración hacia Francia en 1973, con fundamento en la suposición de que los acrecentados ingresos provenientes del petróleo permitirían a Argelia emplear a su propia gente.

La caída en la economía europea ofrecía la imagen del auge de las economías petroleras de los países árabes. En Europa, la crisis petrolera de 1973 anunciaba un periodo de estancamiento económico y de reestructuración que tuvieron, como consecuencia, un aumento en el desempleo estructural y una menor demanda de trabajadores no calificados. Esto acabó por golpear, de manera desproporcionada, a los trabajadores huéspedes y llevó a su desempleo masivo. La mayoría de las sociedades de destino no sólo esperaban que esta migración fuera temporal, sino que también los propios migrantes, situados en una antigua tradición de migración circular (De Haas 2007), pretendían regresar después de ahorrar una cierta cantidad de dinero para comprar tierras, construir una casa o echar a andar su empresa. Sin embargo, en contra de las expectativas, y a pesar de una importante migración de retorno, una cifra alta de migrantes magrebíes acabó por quedarse permanentemente.

No sólo los países europeos, sino también Argelia y Túnez (Fargues, 2004: 13591360) intentaban incitar a los migrantes a que regresaran. No obstante, por lo general fracasaron esas políticas de retorno. Primero, ello se relacionaba con la falta de oportunidades para la reintegración económica en la mayoría de los países de origen. Marruecos y Túnez sufrieron mucho más que los países europeos por los precios petroleros estructuralmente altos y por el declive económico global, comenzando a experimentar un creciente desempleo, mientras que Marruecos entró también en un periodo de inestabilidad política y represión, después de dos fallidos golpes de Estado en contra del Rey Hassan II, en 1971 y 1972.

En segundo lugar, las políticas cada vez más prohibitivas, en particular la puesta en práctica de restricciones en los visados, tuvieron el efecto paradójico de hacer que los migrantes se establecieran permanentemente, en vez de lo contrario (Fargues, 2004; Obdeijn, 1993). Muchos migrantes magrebíes decidieron establecerse no tanto a pesar sino debido a las políticas de inmigración cada vez más restrictivas. Los posibles migrantes de retorno temían que ya no se les permitiera volver a los países receptores, si no lograban readaptarse. En combinación, con la incertidumbre general acerca del desarrollo en el Magreb, esto hizo que los migrantes decidieran «quedarse en el lado seguro» y no arriesgar su residencia en el extranjero (Entzinger, 1985: 263-275).

La posterior reunificación familiar a gran escala anunciaría el cambio de una migración circular a una de carácter más permanente y, además del crecimiento natural y la migración ilegal, este fenómeno explica casi por completo porqué las poblaciones del noroeste de Europa, de origen magrebí, seguían creciendo con tasas relativamente altas durante las décadas de los setenta y ochenta, a pesar de la prohibición formal al reclutamiento. La población registrada de marroquíes en Francia, Bélgica, Holanda y Alemania se incrementó de 400,000, en 1975, a casi un millón en 1992 (de Haas 2007). La cifra registrada de población tunecina en Francia, Alemania, Bélgica, Italia y Suiza 
se duplicó entre 1977 y 1992, de 225,000 a 444,000 (cálculos basados en Gammoudi, 2006). A pesar de la prohibición formal, la migración de Argelia a Francia continuó también, principalmente por medio de la reunificación familiar. El número de descendientes de argelinos (excluyendo a los colons y harkis) en Francia se incrementó de una cifra calculada en 500,000, en 1964, a 800,000 a principios de los años ochenta. ${ }^{5}$

\section{El parteaguas de la Guerra del Golfo en 1991}

Tras un periodo en el que predominó la migración de mano de obra de manera relativamente persistente, desde Egipto hacia los países del Golfo y Libia, así como de migración familiar desde el Magreb a Francia y otros países del noroeste europeo, el panorama de la migración en África septentrional fue testigo de transformaciones de fondo desde fines de los años ochenta. Nuevamente, una serie de levantamientos políticos (Guerra del Golfo, inicio de la guerra civil en Argelia y el embargo de la onu a Libia) ocurridos entre 1991 y 1992 desempeñaron un papel importante en el establecimiento de nuevas tendencias migratorias y en la generación de crecientes vínculos entre los sistemas migratorios del norte y del sur de África, al mismo tiempo que se cristalizaba la posición privilegiada del norte de África en los sistemas euro-mediterráneos de migración, tanto como zona de origen como de tránsito.

La Guerra del Golfo de 1991 originó una repatriación forzada masiva de migrantes provenientes de los países del CCG, entre ellos 700,000 egipcios, desde Irak, Jordania y Kuwait (Baldwin-Edwards, 2005: 28). Estos eventos reforzaron la tendencia ya existente, en los países del Golfo, de apoyarse cada vez más en los inmigrantes asiáticos. Esto se dio junto con los esfuerzos por «indigenizar» la fuerza de trabajo de los países del Golfo, para reducir la dependencia de los migrantes y aliviar el creciente desempleo entre las poblaciones nativas (OIM, 2005: 54, 59). Tales reformas fueron estimuladas por precios del petróleo persistentemente bajos durante buena parte de los años ochenta y noventa.

A pesar del potencial para la migración, en apariencia cada vez menor, la migración egipcia hacia el Golfo ha sido mucho más persistente y permanente de lo que se proponían las políticas. Aun cuando Egipto y los países del CCG clasifican tozudamente a su migración como temporal, Sell (1988) observaba ya que muchos migrantes egipcios permanecen por periodos más prolongados y que se ha dado una sustancial reunificación familiar. Aunque se espera que regresen, miles salen de Egipto cada año con la intención de establecerse, de manera permanente, en el extranjero (Zohry y Harrell-Bond, 2003:31). Ha resultado notablemente difícil poner en práctica la política de indigenización, en tanto los migrantes semilegales siguen entrando por medio de intrincados sistemas de intercambio de visas (orm, 2004: 60), mientras que los migrantes indocumentados en busca de empleo también pueden entrar al país por medio de la realización del hadj, el peregrinaje

\footnotetext{
${ }^{5}$ Fuente: http://www.country-data.com/cgi-bin/query/r-361.html (consultada el 16 de mayo de 2006).
} 
musulmán a La Meca. De hecho, después de la Guerra del Golfo, las tasas de migración volvieron rápidamente a los niveles anteriores a la guerra y la cantidad de contratos laborales se disparó entre 1992 y 1995 (Zohry y Harrell-Bond, 2003: 30, 35).

Sin embargo, se suscitó un cambio cualitativo en la estructura de los mercados de trabajo fuertemente segmentados del CCG, donde los trabajadores nativos asumían las posiciones más altas, en el mercado de trabajo, pero evitaban los empleos de menor nivel en el sector privado relativamente mal pagado (Baldwin-Edwards, 2005:27). Mientras que los inmigrantes asiáticos ocupan cada vez más empleos manuales en los segmentos del mercado laboral en que no se requiere calificación (oIM, 2005:62), los egipcios y otros migrantes árabes hacia el Golfo ocupan cada vez más los segmentos intermedios de los mercados de trabajo del CCG (Zohry y Harrell-Bond, 2003: 35). Los migrantes egipcios no calificados, como quienes trabajan en la construcción, han migrado en números crecientes hacia Jordania (oIM, 2005: 62) y Líbano, países que han reemplazado a Irak como destino para ese tipo de trabajadores. El potencial migratorio en declive para los trabajadores no calificados hacia los países árabes, probablemente, ha estimulado la creciente migración egipcia hacia Italia y Grecia (Zohry y Harrell-Bond, 2005: 7).

Hasta 1990, la historia de la emigración argelina era lo mismo que la historia de la emigración argelina hacia Francia. ${ }^{6}$ Sin embargo, el inicio de la guerra civil en 1991, que acabó con la vida de más de 100,000 personas, implicó un incremento en la migración de refugiados y en la migración económica hacia una diversidad de países europeos (Collyer, 2003).

Otro parteaguas de las migraciones de África septentrional lo constituyó el embargo de armas y de vuelos impuesto sobre Libia por el Consejo de Seguridad de la ONU, entre 1992 y 2000. Desilusionados por lo que ellos percibían como una falta de apoyo de otros países árabes, el coronel Al-Kadafi se embarcó en una reorientación radical de la política exterior de Libia hacia los países subsaharianos (Hamood, 2006: 17). AlKadafi se posicionó como un líder africano y comenzó a motivar a los subsaharianos para trabajar en Libia (Hamood, 2006; Pliez, 2002). En consecuencia, Libia se convirtió en un importante destino y, después de 2000, en una zona de tránsito para los migrantes subsaharianos (Boubakri, 2004). A principios de los años noventa, la mayor parte de los migrantes provenían de los países vecinos de Libia, como Sudán, Chad y Nigeria que, posteriormente, se convirtieron en países de tránsito para los migrantes de países subsaharianos (Bredeloup y Pliez, 2005: 6).

La creciente inmigración subsahariana no puede atribuirse tan sólo a la nueva política panafricana de Libia, sino que también es parte de una tendencia general hacia la reestructuración y segmentación de los mercados de trabajo libios y del norte de África. De manera similar a lo ocurrido con los países del Golfo, una caída económica por la baja en los precios del petróleo y las sanciones condujo a la llamada indigenización, de la fuerza de trabajo libia, ya desde principios de los años ochenta. No obstante, los libios

\footnotetext{
${ }^{6}$ En 1990, la comunidad argelina en Francia se calculaba en más de un millón de personas, las que representaban al 97\% de los argelinos que vivían fuera de Argelia (Collyer, 2003).
} 
no estaban dispuestos a asumir los empleos manuales y no calificados, éstos han sido ocupados cada vez más por los migrantes africanos subsaharianos (Hamood, 2006:18), posiblemente por una voluntad cada vez más escasa, entre los migrantes del norafricanos, para trabajar en Libia. ${ }^{7}$ Este país se ha apoyado, cada vez más, en los migrantes subsaharianos para realizar los trabajos pesados en sectores como la construcción y la agricultura, mientras que los trabajadores egipcios y magrebíes parecen concentrarse, gradualmente, en empleos de mejor estatus en el sector de servicios. ${ }^{8}$

\section{Las nuevas migraciones hacia el sur de Europa}

Desde 1990, los países de la UE han reforzado sus controles fronterizos externos y han hecho más rigurosas sus políticas de visado. No obstante, la migración del norte de África hacia Europa mostró una notable persistencia y una diversificación en términos de los países de destino. La migración a los países de destino ya establecidos -Francia, Bélgica, Holanda y Alemania - se prolongó a través del proceso de formación familiar. Ello se dio, en parte, como consecuencia de la marcada tendencia de los descendientes magrebíes a contraer nupcias con personas de la región de origen de sus padres (Lievens, 1999).

Empero, en especial después de 1995, ocurrió un repunte inesperado en la migración laboral proveniente del Magreb, y también de Egipto, hacia el sur de Europa. En Europa mediterránea, el notable crecimiento en la agricultura de exportación, la construcción y el turismo ha generado un incremento en la demanda de mano de obra temporal, flexible y no calificada (Fargues, 2004: 1357). Hay una alta demanda de mano de obra migrante sin calificación, en especial en los sectores informales relativamente grandes de estos países, en particular de Italia. Esto hace que sea relativamente fácil encontrar trabajo, dada la demanda local de trabajadores de escasa capacitación y que acepten salarios bajos. España e Italia y, en menor grado, Grecia, países que antes fueron exportadores de mano de obra, han emergido como nuevos destinos de importancia para los migrantes marroquíes (a España e Italia), tunecinos (principalmente a Italia), argelinos (sobre todo a España) y egipcios (básicamente a Italia, pero también a Grecia), desde mediados de los años ochenta.

Hasta que Italia y España exigieron visas en 1990 y 1991, respectivamente, los migrantes magrebíes pudieron entrar como turistas y, con frecuencia, seguían un patrón de migración temporal. Sin embargo, dada la sostenida demanda de trabajadores inmigrantes, la introducción de visas y el aumento en los controles fronterizos llevaron al aumento en la migración indocumentada, con mayores costos y peligros durante plazos más prolongados, en vez de que ésta decreciera. Una proporción creciente de los migrantes laborales magrebíes independientes, hacia el sur de Europa, la constituyen

\footnotetext{
En comparación con las oportunidades en Europa, Libia no es un país particularmente atractivo para trabajar, por parte de los migrantes magrebíes. Las políticas de inmigración de Libia han sido muy erráticas (Hamood, 2006: 18), pues los migrantes no tienen derechos y los salarios son considerablemente menores.

${ }^{8}$ Fuente: observaciones del autor en Libia (Tobruk, Benghazi, Trípoli, Zliten), abril de 2005.
} 
mujeres que trabajan como ayudantes domésticas, niñeras, limpiadoras, o en la agricultura y pequeñas industrias (Salih, 2001).

Desde la década de los ochenta ha habido varias ocasiones en que los gobiernos de los países del sur de Europa se vieron obligados a conceder el estatus legal a los migrantes, entre ellos, una gran parte de marroquíes y, en menor grado, argelinos, tunecinos y egipcios. Por ejemplo, entre 1980 y 2004, la población total de marroquíes residentes oficialmente, en España e Italia, se incrementó de cerca de 20,000 a 650,000 (De Haas, 2007). Otro desarrollo es la creciente migración de los países con mayor escolaridad del Magreb hacia Canadá (Québec) y Estados Unidos.

\section{La migración trans-sahariana}

Desde 1995, un grupo compuesto por solicitantes de asilo y migrantes laborales provenientes del África subsahariana, e incluso del Medio Oriente y el sur de Asia, se han unido gradualmente, a los magrebíes, en su cruce del estrecho de Gibraltar hacia España o desde Túnez hacia Italia (Barros et al., 2002; Boubakri, 2004: 3). Desde 2000, las revueltas antiinmigrantes y la creciente represión hacia los migrantes en Libia han incitado, a un número creciente de migrantes subsaharianos, a migrar a otros países del Magreb o a cruzar el Mediterráneo (Hamood, 2006).

Una vigilancia más rigurosa en el estrecho de Gibraltar y en la costa de Túnez por las fuerzas españolas y marroquíes, tunecinas e italianas, han llevado, supuestamente, a una diversificación general en los puntos para intentar el cruce (Boubakri, 2004: 5; De Haas, 2007; Fadloullah et al., 2000: 113-5) desde la costa oriental de Marruecos hasta Argelia, desde la costa de Túnez hasta Libia y desde el oeste del Sahara y, más recientemente, Mauritania y otros países del occidente africano hasta las islas Canarias. Una proporción considerable de migrantes considera a los países de África septentrional como su destino primario, mientras que otra, que no logra o no se aventura a entrar a Europa, prefiere establecerse en el norte de África en vez de regresar a sus países, más inestables y sustancialmente más pobres (Barros et al., 2002; Bredeloup y Pliez, 2005; De Haas, 2007).

\section{CARACTERÍSTICAS ACTUALES DE LA MIGRACIÓN}

La persistente migración proveniente del norte de África, durante las pasadas cuatro décadas, ha llevado al establecimiento de vastas comunidades de migrantes en el extranjero. Debido a que no disponemos de información de series de tiempo acerca de los movimientos migratorios, sólo podemos apoyarnos en los datos de reservas de migrantes para calcular las principales tendencias en las poblaciones provenientes de los países de África septentrional. La figura 1 muestra los datos estimados de reservas (stocks) de descendientes de personas con origen en el norte de África que viven en el extranjero, con base en fuentes de datos de los países de origen. Estas cifras tienden a incluir a la segunda y tercera generaciones, pero pueden excluir a los migrantes indocumentados 
(Fargues, 2005). La figura revela la concentración de la migración magrebí en Europa occidental y de la migración egipcia en los países árabes productores de petróleo.

De un total de ocho millones, se creía que en 2004 vivían, aproximadamente, 4.7 y 2.4 miles de millones de descendientes en Europa y los países árabes, respectivamente (Fargues, 2005). Marruecos posee la mayor población emigrante de todos los países incluidos, con 3.1 millones de expatriados (10.4\% de su población total en 2004), seguido por Egipto (2.7 miles de millones, 3.7\% de la población total), Argelia (1.4 miles de millones, $4.3 \%)$ y Túnez $(840,000,8.5 \%)$. En todos los países, pero particularmente en el caso de Egipto, el subregistro en relación con la migración indocumentada parece jugar un papel adicional.

FIGURA 1

Descendientes de norafricanos, según región de destino.

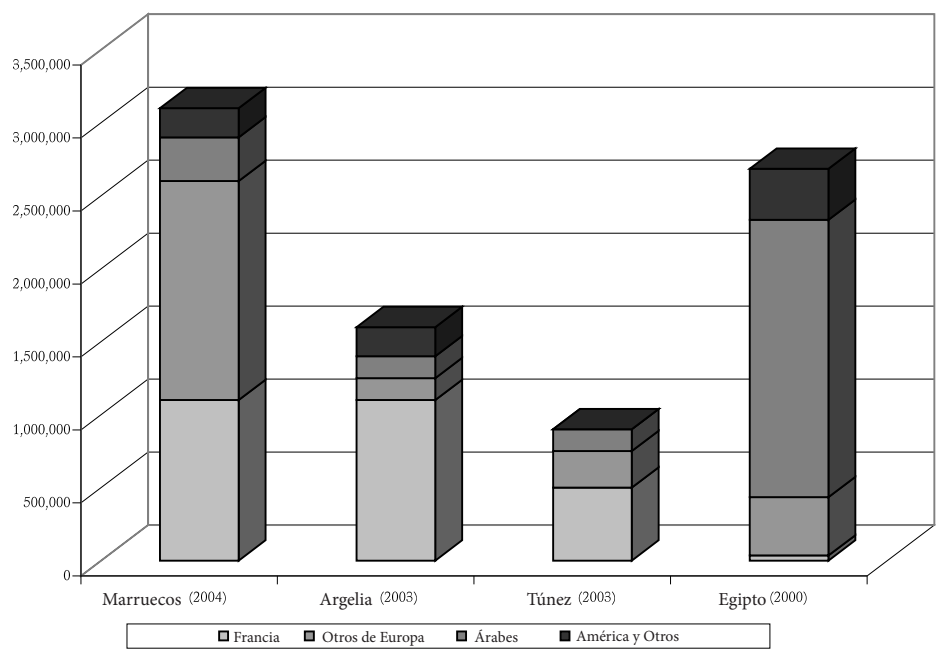

Fuente: Diversas fuentes de los países de origen, citadas en Fargues (2005)

(Marruecos, Túnez, Egipto) y Labdelaoui (2005) (Argelia).

La migración de África septentrional hacia Europa, por lo general, ha incluido la migración de trabajadores no calificados y semicalificados de las áreas rurales que consiguieron empleos manuales en los sectores de la industria, agricultura y servicios. Algunos reclutadores preferían a trabajadores sin educación porque, de ese modo, no resultaban sospechosos de activismo en los sindicatos (De Haas, 2003). Se reporta que la migración se ha tornado más selectiva en lo que se refiere a educación, más urbana y con un mayor componente femenino en las décadas recientes (Salih, 2001; Labdelaoui, 2005). No queda muy claro si ello refleja un verdadero cambio en la selectividad de la migración o procesos generales de urbanización y mejoras en los logros educacionales en los países de origen (Fadloullah et al., 2000: Xvi, 83; De Haas, 2003). No obstante, en Argelia, la dimensión de los refugiados, en la migración mucho más reciente, se señala como un factor que ha contribuido a la emigración selectiva de quienes tienen relativamente más altos niveles de escolaridad (Collyer, 2003). 
La migración desde Egipto hacia el Golfo, tradicionalmente, ha incluido una proporción relativamente alta de profesionistas de alta escolaridad (Schoorl et al., 2000: XVI). La migración altamente calificada que sale de Egipto, y se dirige más allá del mundo árabe, se ha centrado principalmente en Estados Unidos, Canadá y Australia. La emigración calificada de estudiantes y profesionistas del Magreb, tradicionalmente, se centraba en Francia, pero después de 1990 se ha incrementado la orientación hacia Estados Unidos y Canadá. La creciente migración de personas altamente calificadas se relaciona con las altas tasas de desempleo entre los graduados universitarios en el Magreb (Boubakri, 2004: 10; De Haas, 2003) y con una falta generalizada de oportunidades de avance en sus carreras y de satisfacción laboral (Baldwin-Edwards, 2005:4). Con base en un amplio análisis de datos, Fargues et al. (2005) descubrieron un importante patrón por el cual Europa atrae a los de menor escolaridad mientras que Estados Unidos y Canadá logran atraer a los de mayor escolaridad entre los norafricanos.

Una última tendencia es la creciente feminización de la migración de mano de obra desde los países del Magreb, lo que aparentemente coincide con una mejor educación para las mujeres, su emancipación parcial y las altas tasas de desempleo femenino, así como una creciente demanda de trabajadoras domésticas, niñeras, limpiadoras y otros puestos en el sector (informal) de los servicios en Europa (Fadloullah et al., 2000; Labdelaoui, 2005).

FIGURA 1

Evolución de la población de ascendencia marroquí que vive en los principales países receptores 1955-2004.

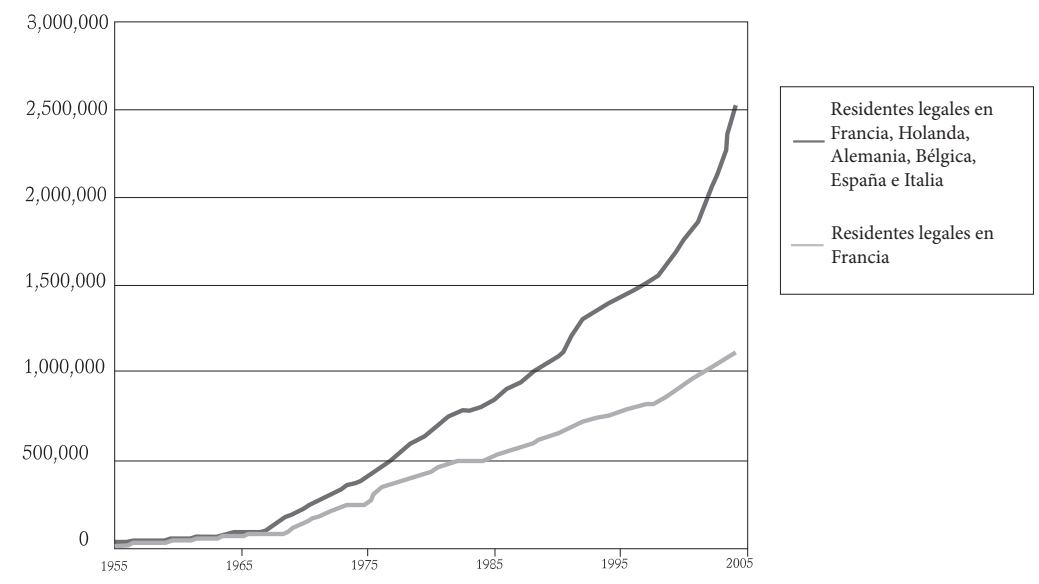

Fuente: Diversas fuentes en De Haas (2007).

\section{Datos en el ámbito nacional}

En las últimas cuatro décadas, Marruecos se ha transformado en uno de los principales países de emigración en el mundo. Los marroquíes no sólo forman una de las más gran- 
des comunidades de migrantes, sino también de las más dispersas en Europa occidental. De una población total de 30 millones, más de tres millones de ascendencia marroquí vivían en el extranjero en 2004. Esto no incluye a los aproximadamente 700,000 judíos de ascendencia marroquí que viven actualmente en Israel (De Haas, 2007). La figura 1 ilustra el notable incremento de la población de origen marroquí en los principales países receptores en Europa, desde fines de los años sesenta, así como la cada vez menor concentración espacial en Francia. Entre 1974 y 2004, las comunidades de expatriados marroquíes, en Europa, han aumentado a una tasa promedio de 72,000 personas al año, desafiando las políticas de inmigración cada vez más restrictivas, aunque parte de ese incremento se da por crecimiento natural. La aceleración posterior a 1997 refleja, en gran parte, las campañas masivas de regularización en Italia y España.

Francia es, todavía, el lugar de destino para la población de mayor magnitud de ascendencia marroquí y con residencia legal (más de 1,100,000), seguido por España $(424,000)$, Holanda (300,000), Italia $(299,000)$, Bélgica $(293,000)$ y Alemania $(102,000)$. Hay comunidades que viven en Estados Unidos $(100,000)$ y Canadá $(78,000)$, constituidas por migrantes de alta escolaridad.

TABLA 2

Ciudadanos marroquíes residentes en el extranjero (2004)

\begin{tabular}{|c|c|c|c|}
\hline \multicolumn{2}{|c|}{ PAís } & \multicolumn{2}{c|}{ PAís } \\
\hline Francia & $1,113,176$ & Argelia & 79,790 \\
\hline Holanda & 300,332 & Libia & 120,000 \\
\hline Alemania & 102,000 & Túnez & 25,637 \\
\hline Bélgica & 293,097 & Otros países árabes & 57,345 \\
\hline España & 423,933 & & \\
\hline Italia & 298,949 & Estados Unidos & 100,000 \\
\hline Reino Unido & 35,000 & Canadá & 77,713 \\
\hline Otros en Europa & 50,384 & & \\
\hline & & Otros & 11,734 \\
\hline Total & $2,616,871$ & Total & 472,219 \\
\hline
\end{tabular}

Fuente: Datos consulares, en Fargues (2005: 231-232).

Aunque Francia es todavía el principal destino de la migración argelina, con más de 1 millón de expatriados reportados en 2003 (Labdelaoui, 2005: 10), se ha dado una diversificación tras el inicio de la guerra civil argelina. Entre 1995 y 2003, la población de origen argelino que vive en Francia se ha incrementado en un 18\%, frente al 113\% en otros países europeos, con los mayores incrementos en España (547\%) e Italia (126\%). Un aumento del $96 \%$ en la presencia argelina, en Alemania, refleja la llegada de refugiados a este país a principios de los años noventa. El mayor incremento ha sido el de la migración a Canadá, que pasó de 10,000 a 35,000 (véase tabla 3). ${ }^{9}$

${ }_{9}^{9}$ Nuestros cálculos se basan en Fargues (2005) y Labdelaoui (2005). 
TABLA 3

Ciudadanos argelinos residentes en el extranjero (alrededor de 2003)

\begin{tabular}{|c|c|c|c|}
\hline \multicolumn{2}{|c|}{ EUROPA } & \multicolumn{2}{c|}{ OTROs } \\
\hline Bélgica & 19,095 & Países árabes & 76,795 \\
\hline Francia & $1,101,253$ & Marruecos $(1995)^{*}$ & 25,000 \\
\hline Alemania & 17,641 & Túnez $(1995)^{*}$ & 30,000 \\
\hline Italia & 13,000 & & \\
\hline España & 45,791 & Canadá & 35,000 \\
\hline Escandinavia & 10,000 & Estados Unidos & 18,000 \\
\hline Reino Unido & 14,152 & & 19,365 \\
\hline Holanda & 7341 & Otros & 149,160 \\
\hline Total & $1,228,273$ & Total & \\
\hline
\end{tabular}

Fuente: Labdelaoui (2005: 12-13) (datos de 2003); ${ }^{*}$ CNES (1997), citado en Fargues (2005: 89-91).

En comparación con Argelia, la emigración tunecina, centrada tradicionalmente más en Francia que la de Marruecos, pero menos que la de Argelia, también se ha diversificado. Además de un estimado de 493,000 descendientes de tunecinos en Francia, aproximadamente 54,000 personas con ascendencia tunecina viven en Alemania (véase tabla 4). En años más recientes, la vecina Italia se ha convertido, rápidamente, en el nuevo destino principal de los migrantes laborales tunecinos.

TABLA 4

Ciudadanos tunecinos residentes en el extranjero (2001-2003)

\begin{tabular}{|c|c|c|c|}
\hline \multicolumn{2}{|c|}{ PAís } & Argelia & 13,554 \\
\hline Francia & 493,028 & Libia & 60,023 \\
\hline Italia & 101,042 & Marruecos & 4,082 \\
\hline Alemania & 53,925 & Otros Países árabes & 7,217 \\
\hline Bélgica & 17,084 & & \\
\hline Suiza & 6,909 & Canadá & 12,347 \\
\hline Holanda & 7,058 & Estados Unidos & 9,800 \\
\hline Otros países de Europa & 16,719 & & 653 \\
\hline & & Otros & \\
\hline África sub-sahariana & 1,149 & Total & 107,676 \\
\hline Asia & 669 & & \\
\hline Total & 697,583 & & \\
\hline
\end{tabular}

Fuente: Datos consulares, Ministère des Affaires Etrangères; en Fargues (2005: 316).

Los servicios egipcios de estadística hacen una distinción formal entre la migración «temporal» a los países árabes y la «migración permanente» a los países occidentales. La tabla 5 muestra el predominio de la migración a Arabia Saudita (924,000 migrantes), 
Libia $(333,000)$, Jordania $(227,000)$ y Kuwait $(191,000)$. Es notable que Estados Unidos $(318,000)$, Canadá $(110,000)$ y Australia $(70,000)$ son los lugares de residencia de las más grandes comunidades egipcias fuera del mundo árabe. Más recientemente, se ha dado la mayor parte de la migración egipcia indocumentada hacia Italia y Grecia (Zohry y Harrell-Bond, 2005:7). Las reservas migratorias reportadas, en los países árabes y en los países del sur de Europa, probablemente sean cifras subestimadas debido a una migración indocumentada bastante sustancial.

TABLA 5

Ciudadanos egipcios residentes en el extranjero por país de residencia

\begin{tabular}{|c|c|c|c|}
\hline \multicolumn{2}{|c|}{ MIGRACIÓN «TEMPORAL» } & \multicolumn{2}{|c|}{ MIGRACIÓN «PERMANENTE» } \\
\hline Bahrein & 4,000 & Australia & 70,000 \\
\hline Irak & 65,629 & Austria & 14,000 \\
\hline Jordania & 226,850 & Canadá & 110,000 \\
\hline Kuwait & 190,550 & Inglaterra & 35,000 \\
\hline Líbano & 12,500 & Francia & 36,000 \\
\hline Libia & 332,600 & Alemania & 25,000 \\
\hline Omán & 15,000 & Grecia & 60,000 \\
\hline Katar & 25,000 & Holanda & 40,000 \\
\hline Arabia Saudita & 923,600 & Italia & 90,000 \\
\hline Emiratos AU & 95,000 & España & 12,000 \\
\hline Yemen & 22,000 & Suiza & 14,000 \\
\hline & & Estados Unidos & 318,000 \\
\hline Total & $1,912,729$ & Total & 824,000 \\
\hline
\end{tabular}

Fuente: CAPMAS 2000 y 2001, en Fargues (2005: 109).

FIGURA 2

Migración intra-regional neta estimada con base en datos de reservas de población migrante $(2002-2004)^{10}$

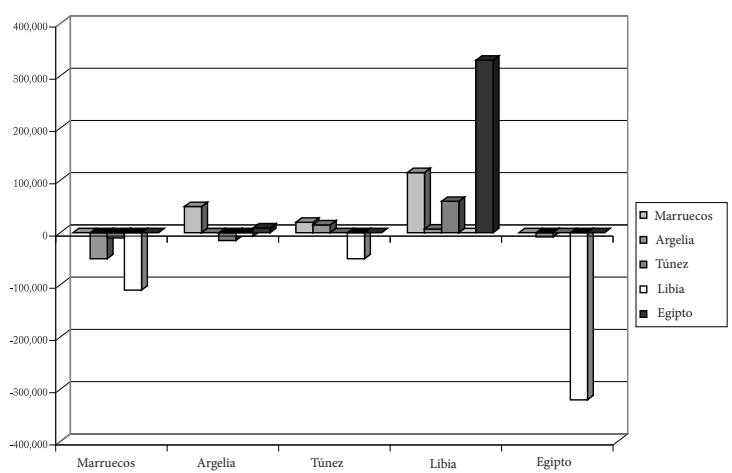

Fuente: Elaboración propia con base en diversas fuentes citadas en Fargues (2005).

\footnotetext{
${ }^{10}$ Los datos argelinos sobre poblaciones expatriadas corresponden a 1995.
} 
A partir de los datos de poblaciones migrantes podemos estimar el movimiento neto migratorio intra-regional. La figura 2 ilustra el papel de Libia como país de recepción de migrantes provenientes de la misma región, en particular de Egipto. No obstante, estas cifras probablemente son una subestimación del verdadero nivel de movilidad intra-regional. En especial los migrantes a corto plazo tienen pocas probabilidades de registrarse ante sus consulados.

\section{Inmigración}

No hay datos confiables sobre el creciente número de migrantes subsaharianos que viven en los países de África septentrional. Alioua (2005) calcula que la cantidad de migrantes y refugiados subsaharianos que viven en Marruecos alcanza varias decenas de miles. Las autoridades libias locales estiman la cifra de trabajadores extranjeros legales en 600,000, mientras que los inmigrantes ilegales se estima que se sitúan entre 750,000 y 1.2 millones (Bredeloup y Pliez, 2005: 6; EC, 2004). Otra fuente afirma que Libia alberga entre 2 y 2.5 millones de inmigrantes (incluidos 200,000 marroquíes, 60,000 tunecinos y de 20,000 a 30,000 argelinos, además de 1 a 1.5 millones de africanos subsaharianos), lo que representa del 25\% al 30\% de su población total (Boubakri, 2004:2). El Cairo alberga a una de las más grandes poblaciones de refugiados en el mundo, principalmente nacionales de Sudán, palestinos, somalíes, etíopes y nacionales de Eritrea. La actual población de refugiados y migrantes en Egipto (principalmente en El Cairo) se estima en niveles situados entre 0.5 y 3 millones (Zohry y Harrell-Bond, 2003: 49).

\section{LA DIMENSIÓN DEL DESARROLLO EN LA MIGRACIÓN:}

\section{EL CASO DE MARRUECOS}

\section{Migración y remesas como \\ estrategia nacional de desarrollo}

Para los cuatro países de emigración norafricanos, la migración ha jugado un importante papel para aliviar las tensiones del mercado de trabajo. Marruecos, Túnez y, desde 1971, Egipto han establecido una persistente política para estimular la migración, de manera abierta o tácita, como herramienta de desarrollo. En tanto que la actitud del gobierno argelino hacia la migración ha sido más ambivalente, adoptando, gradualmente, una modalidad de laissez faire hacia la emigración, en buena parte por necesidad económica.

Cuando los países de origen y destino cayeron gradualmente en la cuenta de que muchos migrantes regresarían, las políticas gubernamentales se enfocaron, cada vez más, en medidas que aseguraran la llegada de las remesas monetarias, estimularan las inversiones de los migrantes, así como en políticas simbólicas dirigidas a fortalecer los lazos entre las poblaciones expatriadas y sus terruños imaginados o reales (Fargues, 2004). Para ilustrar los impactos de la migración sobre el desarrollo en lo que respecta a 
las políticas para estimular ese impacto, esta sección se concentra en el caso de Marruecos, el país de emigración más prominente de la región.

Durante el periodo posterior a la independencia, el gobierno marroquí ha estimulado, activamente, la emigración por razones políticas y económicas. La migración internacional era vista como una «válvula de seguridad» para evitar tensiones en ciertas áreas rurales, con población predominantemente berebere (Rif, Sous y en los oasis del sureste), que tienen una reputación de rebeldía frente al gobierno central «árabe» (De Haas, 2007). Estas políticas fueron puestas en práctica, principalmente, por medio de la reglamentación para la emisión de pasaportes y promoviendo que los reclutadores operaran en esas áreas.

Además de ser un instrumento político, la migración también era vista como una herramienta para el desarrollo económico nacional. La utilidad de la migración se percibía, principalmente, a través de las habilidades y conocimiento que se esperaba que adquirieran los migrantes al trabajar y estudiar en el extranjero. Sin embargo, la creencia de que los migrantes serían actores del cambio, gradualmente, se desvaneció durante los años setenta. En general, fracasaron los esfuerzos para estimular los programas de migración de retorno y de inversión de los migrantes, debido, primordialmente, a un clima poco favorable para la inversión y una desconfianza generalizada de los migrantes ante las agencias gubernamentales (Fadloullah et al., 2000: 32; Obdeijn, 1993).

En contraste con las políticas dirigidas a estimular las inversiones de los migrantes, han tenido más éxito las políticas para incrementar las transferencias de remesas por medio de la creación de una red de consulados, oficinas de correos y sucursales bancarias en el extranjero, promovidas durante los años setenta y ochenta. Al mismo tiempo, el gobierno marroquí intentó mantener un estrecho control de las comunidades migrantes, en Europa, a través de una red de control y con un entramado de espionaje en el extranjero. Hasta principios de los años noventa, el gobierno se opuso, activamente, a la integración de los migrantes en los países de destino, por el temor a que los migrantes formaran una oposición política «desde afuera». La integración se percibía, asimismo, como un peligro para las transferencias encarnadas de las remesas (De Haas y Plug, 2006).

\section{Del control de los emigrantes al cortejo de las diásporas}

A pesar de todo, un ominoso estancamiento de las remesas en los años noventa y una creciente conciencia de que las políticas represivas alejaban más a los migrantes, en vez de ligarlos más estrechamente con el gobierno marroquí, éste optó por adoptar una actitud más positiva (De Haas y Plug, 2006). Esto se combinó con un proceso de relativa liberalización política y una mejora substancial en el renglón de los derechos humanos. Además, un giro de corte neoclásico en las políticas económicas implicó la desregulación y la apertura de la economía de Marruecos. Tras años de escepticismo, se generó también una renovada esperanza en el papel que los migrantes podían desempeñar al estimular la inversión extranjera directa. 
Todo ello ha tenido, como consecuencia, una actitud más positiva hacia la naturalización, la doble ciudadanía y el derecho al voto para los migrantes en el extranjero. Esto, a su vez, marcó una notable reversión en el análisis de la política por la cual la integración de los migrantes ya no se ve como un peligro, sino como un proceso benéfico que permite, a los migrantes, enviar más dinero a sus lugares de origen e invertirlo ahí (De Haas, 2007). El aumento de las libertades civiles en general implicó, asimismo, una mayor libertad para que los migrantes establecieran asociaciones berebere, culturales y «de oriundos» (Lacroix, 2005). En noviembre de 2005, el Rey Mohammed vi anunció que los migrantes recibirían el derecho a votar. No obstante, el gobierno marroquí no ha abandonado algunas de sus medidas de política que le permiten ejercer un cierto grado de control. Esto es más palpable en la sistemática oposición de Marruecos a que los descendientes de marroquíes, en Europa, renuncien a la ciudadanía marroquí.

\section{FIGURA 3}

Volumen total de las remesas en flujos oficiales, asistencia oficial para el desarrollo y fondos de inversión extranjera directa hacia Marruecos (1960-2003)

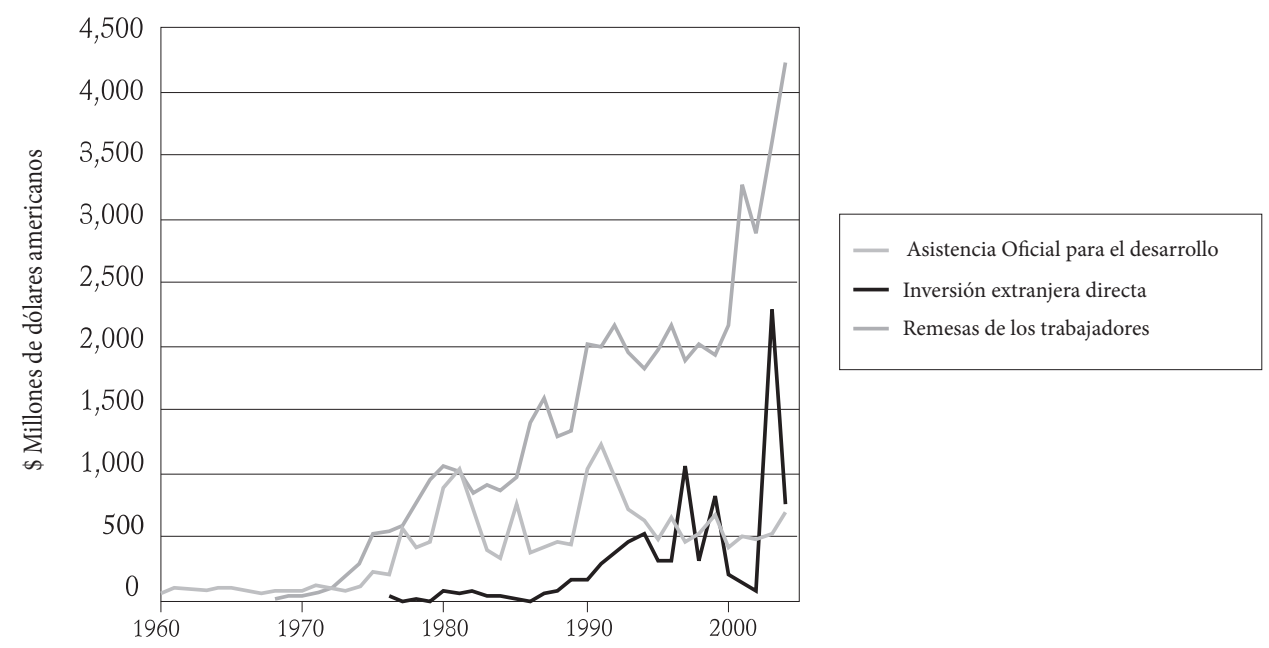

Fuente: Office des Changes Maroc, Anuario Estadístico de la Balanza de Pagos del Fmi.

Además de establecer un ministerio para los marroquíes que residen en el extranjero, el gobierno de Marruecos estableció la Fondation Hassan II pour les Marocains Résidant à l'Étranger que pretende reforzar los vínculos con los emigrantes marroquíes. El gobierno también ha comenzado a reducir los largos lapsos de espera, la corrupción y el hostigamiento de los funcionarios en las fronteras y dentro de Marruecos, en contra de los migrantes durante sus vacaciones. Es probable que esto haya contribuido al enorme incremento en la cifra de migrantes que entraron a Marruecos por las puertas del norte durante las vacaciones de verano, de 848,000 en 1993 a 2.2 millones en 2003. Por el lado económico, se han aplicado nuevas políticas monetarias en Marruecos desde finales de la década de los ochenta, entre ellas, el retiro de las limitaciones de cambio de divisas y en 
la repatriación del dinero (De Haas y Plug, 2006). Se ha estimulado aún más la llegada de remesas por medio de políticas fiscales que favorecen a los migrantes (Refass, 1999: 98).

A primera vista, las nuevas políticas marroquíes ante la diáspora parecen haber revertido el anterior estancamiento en las remesas. En 2001 se suscitó un incremento espectacular en las remesas, hasta alcanzar 3.3 miles de millones de dólares desde un nivel de 2.2 miles de millones de dólares en 2000. Este incremento se atribuye, en parte, al llamado «efecto euro», el concomitante lavado de dinero ${ }^{11}$ y, quizá, el efecto del 9/11. No obstante, tras una breve caída en 2002, las remesas han mostrado una continuada tendencia ascendente en los años posteriores, hasta alcanzar la cifra sin precedentes de 4.2 miles de millones de dólares en 2004 (véase la figura 3).

Sin embargo, la solidez estructural de las remesas marroquíes se explica, sobre todo, por la persistencia no prevista de la migración hacia el noroeste europeo; la duración inesperada de los vínculos transnacionales y transgeneracionales entre los migrantes y quienes «se quedan», y, finalmente, asimismo importante, la nueva migración hacia España e Italia (De Haas y Plug, 2006). Además, el notable incremento en la cifra de los migrantes que visitan Marruecos parece haber contribuido a las remesas.

De tal forma, el instrumento más efectivo para asegurar las remesas ha sido asegurar que continúe la migración y estimular que los migrantes regresen durante las vacaciones. No obstante, las políticas dirigidas a atraer las remesas, la expansión de los servicios financieros, la baja inflación y la ausencia de un extenso mercado para las divisas extranjeras también han estimulado las remesas y pueden explicar porqué Marruecos ha sido relativamente exitoso en canalizar las remesas por las vías oficiales, en comparación con otros países de emigración en el área. ${ }^{12}$

\section{Los impactos de la migración internacional en el desarrollo}

Para el gobierno marroquí, las remesas constituyen una fuente crucial y relativamente estable de divisas extranjeras y se han convertido en un elemento vital para sostener la balanza de pagos de Marruecos. Las remesas han resultado una fuente sustancialmente superior y menos volátil de divisas extranjeras que la ayuda oficial para el desarrollo (AOD) y que la inversión extranjera directa (IED) (De Haas y Plug, 2006) (véase figura 3).

Para los hogares, la migración internacional, con frecuencia, es una forma extremadamente efectiva de mejorar su situación financiera y sus condiciones de vida. Se

\footnotetext{
${ }^{11}$ Se ha afirmado que la introducción del Euro ha incitado, a los marroquíes que viven en Marruecos, a convertir su efectivo, en divisas anteriores al Euro, en dirhams marroquíes. El efecto del Euro podría aplicarse en particular a Holanda, en donde la mayoría de los inmigrantes marroquíes proviene de la región del Rif, zona en la que el contrabando y el comercio del hashís tienen gran presencia y circulan grandes cantidades de efectivo en divisas extranjeras (de Haas y Plug, 2006).

${ }^{12}$ Las remesas en especie, bajo la forma de bienes que se llevan a Marruecos como regalos o mercancía por parte de los migrantes, se estima que representan un cuarto o un tercio de las remesas oficiales (Refass, 1999: 100-102).
} 
calcula que 1.17 millones, de entre treinta millones de marroquíes, caerían en la pobreza absoluta sin las remesas internacionales (Teto, 2001). En regiones con alta emigración internacional, la contribución de las remesas al crecimiento del ingreso de los hogares puede ser mucho mayor (De Haas, 2006b; Schoorl et al., 2000).

Una revisión reciente de la literatura empírica sobre los impactos en el desarrollo en Marruecos (De Haas, 2006b) mostró que esa migración y las remesas han mejorado, considerablemente, las condiciones de vida, la educación de los niños y ampliado la actividad económica en regiones de expulsión de migrantes a través de la inversión agrícola, en bienes raíces y en negocios, actividad de la que se benefician, indirectamente, quienes no emigran por medio del efecto multiplicador del ingreso y en el empleo. Esto cuestiona la visión convencional de que los migrantes caen en el consumo suntuario. Parece darse una secuencia en la que el gasto en los bienes de consumo duraderos y la inversión en bienes raíces se suscitan relativamente pronto en el ciclo migratorio, mientras que las inversiones agrícolas y en negocios no agrícolas se inician tan sólo después de una o dos décadas de migración.

Por medio de las inversiones en bienes raíces urbanas, inversión en negocios y el gasto en el consumo, los hogares vinculados con la migración internacional, simultáneamente, han capitalizado y contribuido a la concentración de actividades económicas en los centros urbanos existentes y en los pueblos de rápido crecimiento a causa de la migración. Lo anterior ha transformado las regiones de expulsión de migrantes como Rif, Sous y los oasis del sur en áreas relativamente prósperas que, ahora, atraen migrantes internos «de reemplazo» (reverse internal migrants) desde áreas más pobres.

$\mathrm{Al}$ ofrecer nuevas oportunidades de supervivencia, la migración también ha permitido que los miembros de grupos socioeconómicos anteriormente subalternos, como los haratin en el sur de Marruecos, escapen de las limitaciones que les imponía la sociedad tradicional. En vez de incrementar o reducir, en sí misma, la desigualdad dentro de la comunidad, la migración ha generado nuevas formas de inequidad dentro de la comunidad, en gran parte con base en las remesas internacionales, las que se han superpuesto a las formas «tradicionales» de inequidad basada en factores hereditarios, como la complexión, la etnicidad o la propiedad de tierras.

No obstante, las clases de ingresos medio y alto se benefician de las remesas, en un grado relativamente mayor, en comparación con los grupos de ingresos más bajos, porque la migración misma ha resultado ser un proceso cada vez más selectivo (Teto, 2001). En comparación con los años sesenta y setenta, debido a las políticas restrictivas en materia de migración, el acceso a la migración internacional se ha tornado gradualmente más selectivo en lo que se refiere a la riqueza y depende más del acceso a redes de migrantes internacionales apoyadas en lazos de parentesco (De Haas, 2006b).

Aunque es frecuente que los impactos de la migración sean más positivos de lo que solía suponerse, también queda claro que los impactos de la migración son heterogéneos en el espacio así como en los grupos socioétnicos y de género, tendiendo a cambiar con el tiempo y los ciclos de migración en los hogares. Más importante todavía, también hay coincidencia en que el potencial de la migración para el desarrollo no se logra plenamente debido a varias limitaciones estructurales en el desarrollo. Éstas incluyen el clima 
generalmente poco favorable para las inversiones, caracterizado por una infraestructura inadecuada y por la ausencia de servicios públicos; por mercados débiles en cuanto al crédito y los seguros; un excesivo burocratismo y mucha corrupción; las dificultades de obtener títulos de propiedad; un frágil sistema jurídico y falta de seguridad legal, así como una falta general de confianza en las instituciones del gobierno y dudas en cuanto a la futura estabilidad política y económica (Bencherifa y Popp, 2000; De Haas, 2006b).

Como ya observa Heinemeijer et al. (1977), aunque los migrantes muestran una disposición relativamente alta a invertir, las oportunidades de inversión para los migrantes en sus regiones de origen suelen ser limitadas. En este sentido, es importante observar que no existe un impacto predeterminado de la migración en el desarrollo. Después de todo, según sea el contexto específico de desarrollo, la migración y las remesas pueden dar, a la gente, la posibilidad y la libertad de retirarse de las actividades sociales y económicas de los países de origen, así como pueden ofrecerlas para invertir en ellas (De Haas, 2006b).

\section{CONCLUSIÓN}

El peligro inmanente de concebir «el» sistema migratorio del norte de África sería asumir un falso grado de unidad regional y de rasgos en común en las experiencias nacionales de migración. Las experiencias de migración internacionales específicas de los países de África septentrional y de las regiones dentro de ellos revelan marcadas diferencias. Por ello, parece más adecuado concebir, el norte de África, como una región en la que los países se conectan con varios sistemas migratorios transcontinentales e interregionales que se traslapan en diversos grados. En el nivel más general, podemos hacer una distinción entre los principales países del Magreb (Marruecos, Argelia y Túnez), que se han integrado sólidamente en el sistema Euro(UE)-Mediterráneo y Egipto, que está conectado, primordialmente, con el sistema migratorio del Golfo (CCG) y otros países árabes como Libia, Jordania y Líbano. No obstante, en la última década se ha incrementado la migración egipcia hacia Europa.

Un enfoque unilateral en la masiva migración neta que se da desde el norte de África, asimismo, ocultaría la existencia de un subsistema migratorio intra-regional centrado en Libia. Este país no sólo se ha convertido en el principal polo intra-regional de la migración, sino que las políticas libias panafricanas de los años noventa también han jugado un importante papel para apoyar la migración trans-sahariana hacia el norte de África, lo que ha llevado a la progresiva integración de los sistemas migratorios norafricanos y subsaharianos.

Las transformaciones que han tenido lugar en estos sistemas migratorios del norte de África no pueden entenderse sin tomar en cuenta los cambios más amplios en el contexto del desarrollo político y económico. Las tendencias generales de la migración se han visto fuertemente afectadas por las guerras (coloniales, civiles y entre estados) así como por importantes cambios políticos y económicos. El proceso de colonización, en un principio, iba paralelo con el de inmigración, en particular en Argelia, pero los 
procesos concomitantes de formación estatal, de penetración capitalista, de desarrollo de infraestructura y de crecimiento poblacional, en combinación con la demanda de mano de obra migrante en los países europeos y, en una etapa posterior, en los del Golfo, pronto generaría un movimiento contrario de emigración. De igual manera, los principales puntos de inflexión como la crisis petrolera en el Golfo, la política egipcia de la infitah, la guerra del Golfo de 1991 y la guerra civil argelina, junto con el embargo en contra de Libia, desencadenaron nuevas formas de migración.

Esos cambios generales también abrieron espacios para políticas migratorias específicas de los gobiernos de los países de origen y destino. Por medio de políticas de reclutamiento, expedición selectiva de pasaportes y visas de salida, los gobiernos han desempeñado un papel decisivo en el desarrollo de patrones de migración, tras lo cual esos patrones iniciales, por su parte, tendieron a cobrar su propio momento (Castles, 2004; Massey, 1989). La persistencia de la migración de África septentrional hacia Europa, a lo largo de los años noventa, ilustra la limitada capacidad de las políticas migratorias específicas para contrarrestar la demanda estructural de mano de obra migrante y los mecanismos de facilitación de la migración que operan a través de las redes.

El caso del norte de África ejemplifica la «permanencia de la migración temporal» (Martin, 1999). Aun cuando los gobiernos de países receptores en Europa y el Golfo han insistido en que la migración era temporal, incluso los gobiernos autoritarios del Golfo han sido incapaces de evitar el establecimiento a largo plazo y la considerable inmigración indocumentada. Paradójicamente, las políticas restrictivas de inmigración en Europa incluso han obligado, hasta cierto grado, a que la gente se establezca de manera permanente.

La literatura parece sugerir que pueden pasar varias décadas antes de que los impactos positivos de la migración en el desarrollo se manifiesten por completo, para que los migrantes «integrados» y establecidos tengan más capacidad de envío e inversión y para que los migrantes que poseen derechos de residencia o la doble ciudadanía muestren una mayor propensión a retornar y circular. Esto arroja dudas en torno a la suposición de que los programas temporales de migración sean efectivos y favorezcan el desarrollo en los países de origen.

El caso marroquí muestra que las políticas orientadas a incrementar las remesas, por medio de canales formales o a estimular las inversiones, sólo pueden tener éxito si coinciden con una estabilidad macroeconómica general y una infraestructura bancaria. Aunque la migración y las remesas han permitido a los hogares incrementar sus ingresos y mejorar radicalmente sus condiciones de vida, la migración es, sin embargo, un fenómeno demasiado limitado como para diluir las limitaciones estructurales del desarrollo.

Aunque las «políticas de la diáspora» pueden desempeñar un cierto rol positivo, éstas tienen efectos limitados si no se acompañan de una reforma y progreso generalizados. La única manera legítima de liberar el potencial para el desarrollo de la migración y de los recursos de los migrantes parece ser la de crear ambientes atractivos para la inversión, generar crecimiento económico y fortalecer la confianza en las instituciones políticas y legales de los países de origen, junto con políticas de inmigración razonables que no inhiban la circulación de los migrantes. 
En el sur de Europa en particular, es probable que una combinación de tasas de baja fecundidad sin precedentes y la presencia de grandes y crecientes sectores informales mantenga la demanda de mano de obra migrante no calificada (y calificada). Las amplias redes de migrantes y la extensa costa del sur de Europa hacen que esta migración sea señaladamente difícil de controlar. A pesar de todo, esto no implica que los actuales patrones migratorios necesariamente hayan de persistir. En las últimas dos décadas los límites entre los sistemas migratorios norafricanos se han difuminado cada vez más, al tiempo que la notable diversificación y difusión de los itinerarios migratorios apuntan a una creciente complejidad en los sistemas migratorios. Esto resalta la necesidad de conceptualizar y explicar al cambio en los sistemas migratorios establecidos (Collyer, 2003).

Al combinar la noción espacial de sistemas migratorios con la noción temporal de transiciones migratorias podemos pensar que la transformación de los países del sur de Europa, en países de inmigración, ha provocado el traslado hacia el sur de la «frontera laboral» euro-mediterránea, un desarrollo que ha ofrecido renovadas y más fuertes oportunidades de migración laboral para los países de África septentrional, los que, a su vez, parecen situarse en el punto más alto de su curva migratoria. El reto a responder aquí es si la creciente migración trans-sahariana hacia los países del norte de África anuncia, de hecho, su futura transición hacia países de inmigración para los países subsaharianos y otros más, como sugiere la teoría de la migración de transición (De Haas, 2007).

Algunas tendencias actuales podrían constituir un aviso de esa transición. No obstante, también debemos estar conscientes de la evolución y estructura interna específicas asociadas a la creciente complejidad de la segmentación de los mercados laborales norafricanos, para comprender la paradoja de la emigración sostenida desde la mayor parte de los países del norte de África y lo que parece ser el establecimiento de los migrantes subsaharianos en los mismos países. Esas «jerarquías migratorias» tan complejas no pueden explicarse con los simples modelos de expulsión-atracción. Incluso en los países más pobres del Magreb existe un notable desempleo estructural entre los nativos con más alta escolaridad que, al mismo tiempo, evitan los trabajos que no requieren de calificación. El crecimiento económico en algunas partes del norte de Túnez y Marruecos, así como la migración a esas zonas, pueden indicar, efectivamente, un cambio futuro hacia el sur de la frontera laboral euro-mediterránea que atraviese el mediterráneo, adentrándose más en África septentrional.

Estas tendencias pueden reforzarse por las transiciones demográficas. La mayor parte de los países africanos ya casi han alcanzado el punto en el cual las dramáticas reducciones en la fecundidad, desde los años setenta, desembocarán en la reducción del número de personas que llegue a la edad laboral, iniciando en 2010 para llegar a su momento más álgido en el periodo 2015-2020. Las siguientes generaciones que entren al mercado de trabajo, en teoría, habrán de enfrentar menor competencia en el mercado laboral y, también, habrán de sobrellevar una carga demográfica relativamente ligera en comparación con las generaciones pasadas y futuras (Fargues, 2004).

Eventualmente, esto puede llevar a una decreciente emigración internacional y a una creciente inmigración laboral proveniente de los países subsaharianos. El que se suscite y el grado que alcance esa transición migratoria, en la realidad, depende en gran medida de 
la reforma política y económica interna que conduzca a la democratización, la estabilidad y a ambientes de inversión más atractivos. Empero, ello también está ligado a varios factores exógenos, en particular, a la manera en que los acuerdos de asociación con la UE hayan de ponerse en marcha y cómo afectarán la competitividad y en qué grado la integración del mercado aumentará el acceso de los productores norafricanos al mercado de la UE.

En el corto plazo, incluso la integración económica exitosa podría estimular la migración. El ajuste a los nuevos ambientes de mercado y de política nunca es instantáneo, en tanto que los impactos negativos de la liberalización del comercio (en sectores protegidos) frecuentemente son inmediatos. La expansión de la producción en sectores potencialmente favorecidos por las reformas comerciales siempre lleva tiempo, cosa que parece una receta para generar un incremento migratorio al inicio de las reformas comerciales (Martin y Taylor, 1996:52). Además, el desarrollo económico y el aumento del comercio y el transporte probablemente permitan que más gente migre al extranjero, al menos en el corto plazo.

Con todo, la genuina integración de mercado, en combinación con la reforma política y económica interna en el largo plazo, podría, efectivamente, conducir a un crecimiento económico sostenido y a la transformación de los países del norte de África en importadores de mano de obra. Si tal fuese el caso, el desarrollo económico y la democratización también podrían incitar, a los migrantes, a invertir así como a retornar y, por tanto, a reforzar aún más estas tendencias positivas. En el pasado reciente tal ha sido el caso en países como España, Italia, Corea del Sur y Taiwán. Sin ese desarrollo más amplio, es probable que la migración continúe también en el largo plazo. La paradoja es que el desarrollo en las sociedades de origen de la migración es un requisito previo para la circulación, el retorno y la inversión por parte de los migrantes, en vez de ser una consecuencia de la migración.

\section{BIBLIOGRAFÍA}

BADUel, Pierre Robert (1980), Société et émigration temporaire au Nefzaoua (Sud-Tunisien), Editions du CNRs, París.

Baldwin-Edwards, Martin (2005), Migration in the Middle East and Mediterranean, Mediterranean Migration Observatory, Greece.

Barros, Lucile, Mehdi Lahlou, Claire Escoffier, Pablo Pumares and Paolo Ruspini (2002), L'immigration Irrégulière Subsaharienne à Travers et Vers le Maroc, ILO, Ginebra.

Bencherifa, Abdellatif and Herbert Popp (2000), Rémigration Nador III, L.I.s. Verlag $\mathrm{GmbH}$, Passau.

BOUBAKRI, Hassen (2004), Transit migration between Tunisia, Libya and Sub-Saharan Africa: study based on Greater Tunis, Council of Europe, Estrasburgo.

BRedeloup, Sylvie and Olivier Pliez (2005), «Editorial: Migrations entre les deux rives du Sahara», Autrepart, 4(36), pp. 3-20.

Castles, S. (2004), «Why Migration Policies Fail», Ethnic and Racial Studies, 27(2), pp.

205-227. 
Castles, S. (2006), «Back to the Future? Can Europe meet its Labor Needs through Temporary Migration?», IMI working paper 1, International Migration Institute, University of Oxford, Oxford. Disponible en http://www.imi.ox.ac.uk/pdfs/ wp1-backtothefuture.pdf (23 de mayo de 2006).

CHOUCRI, N. (1977), «The New Migration in the Middle East: A Problem for Whom?», International Migration Review, 11(4), pp. 412-43.

COlLyer, Michael (2003), Explaining Change in Established Migration Systems: The Movement of Algerians to France and the UK, Sussex Migration Working Paper No. 16, University of Sussex, Sussex Centre for Migration Research.

DE HAAs, Hein (2003), Migration and Development in Southern Morocco: The Disparate Socio-Economic Impacts of Out-Migration on the Todgha Oasis Valley, Unpublished PhD Thesis, University of Nijmegen, Nijmegen.

DE HAAS, Hein (2005), «International migration, remittances and development: myths and facts», Third World Quarterly, 26(8), pp. 1269-1284.

DE HAAS, Hein (2006a), Turning the tide? Why development instead of migration policies are bound to fail, IMI working paper 2, International Migration Institute, University of Oxford, Oxford. Disponible en http://www.imi.ox.ac.uk/pdfs/wp1backtothefuture.pdf (23 de mayo de 2006).

DE HAAS, Hein (2006b), «The impact of international migration on social and economic development in Moroccan sending regions: a review».

DE HAAS, Hein (2007), «Morocco's migration experience: A transitional perspective», Forthcoming in International Migration.

DE HAAS, Hein y Roald Plug (2006), «Trends in migrant remittances from Europe to Morocco 1970-2005», International Migration Review 40(3).

entZinger, H. (1985), «Return Migration in Western Europe», International Migration, 23(2), pp. 263-90.

FADloullah, Abdellatif, Abdallah Berrada y Mohamed Khachani (2000), «Facteurs d’Attraction et de Répulsion des flux Migratoires Internationaux. Rapport National: Le Maroc», Commission Européenne, Rabat.

fargues, Philippe (2004), «Arab Migration to Europe: Trends and Policies», International Migration Review, 38(4), pp. 1348-1371.

fargues, Philippe (ed.) (2005), Mediterranean Migration-2005 Report, Cooperation project on the social integration of immigrants, migration, and the movement of persons, financed by the EC MEDIA Programme, EUI-RSCAS, CARIM Consortium.

FAWCETT, J.T. (1989), «Networks, Linkages, and Migration Systems», International Migration Review, 23(3), pp. 671-80.

Gammoudi, Taoufik (2006), L'Impact de l'Emigration sur la Région de Départ: Cas de l' oasis continentale de Fatnassa, Mémoire de Mastère, Université du 7 novembre à Carthage.

GURAK, Douglas T. y Fe Caces (1992), «Migration Networks and the Shaping of International Migration Systems», M. M. Kritz, L. L. Lim y H. Zlotnik (eds.), International migration systems: A Global Approach, Clarendon Press, Oxford, pp. 150-76. 
HAMOOD, Sara (2006), African transit migration through Libya to Europe: the human cost, FMRs / AUC, El Cairo.

hatton, Timothy J. y Jeffrey G. Williamson (1998), The Age of Mass Migration: Causes and Economic Impact, Oxford University Press, New York.

heinemeijer, W.F., J.A. van Amersfoort, W. Ettema, P. De Mas y H. Van der Wusten (1977), Partir pour Rester: Incidences de 1'Emigration Ouvriére á la Campagne Marocaine, SGI/REMPLOD, La Haya.

IOM (2005), World Migration 2005, IOM, Ginebra.

KRITZ, Mary M.; Lin Lean Lim y Hania Zlotnik (eds.) (1992), International Migration Systems: A Global Approach, Clarendon Press, Oxford.

Labdelaoui, Hocine (2005), Migration et Développement en Algérie, BIт, Ginebra.

LACRoIx, T. (2005), Les réseaux marocains du développement: Géographie du transnational et politiques du territorial, Presses de Sciences Po, París.

Lievens, J. (1999), «Family-forming Migration from Turkey and Morocco to Belgium: The Demand for Marriage Partners from the Countries of Origin», International Migration Review, 33(3), pp. 717-44.

Mabogunje, A.L. (1970), «Systems Approach to a Theory of Rural-Urban Migration», Geographical Analysis, 2(1), pp. 1-18.

MARTIn, Philip L. (1993), Trade and Migration: NAFTA and Agriculture, Institute for International Economics, Washington D.c.

MARTin, Philip L. (1999), "Guest Worker Policies: An International Survey», Ann Bernstein y Myron Weiner (eds.), Migration and Refugee Policies: An Overview, Pinter, Londres.

MARTin, Philip L. y J. Edward Taylor (1996), «The Anatomy of a Migration Hump», J. Edward Taylor (ed.), Development Strategy, Employment, and Migration: Insights from Models, OECD, Development Centre, París, pp.43-62.

MASSEy, Douglas S. (1989), International Migration in Comparative Perspective, Commission for the Study of International Migration and Co-operative Economic Development, Washington, D.C.

MASSEY, Douglas S. (1991), «Economic Development and International Migration in Comparative Perspective», en S. Díaz-Briquets, y S. Weintraub (eds), Determinants of Migration from Mexico, Central America, and the Carribean, Westview Press, Boulder, Colorado, pp. 13-47.

MUUs, Philip (1995), «L'Emigration Marocaine vers l'Europe: Changement et Continuité», Le Maroc et La Hollande. Une Approche Comparative des Grands Interêts Communs, Université Mohammed v, Rabat, pp. 197-202.

OBDEIjN, Herman (1993), «Op Weg naar Werk ver van Huis: Marokkaanse Emigratie in Historisch Perspectief», Migrantenstudies, 9(4), pp. 34-47.

PLIEZ, Olivier (2005), «Vieux reseaux et nouvelles circulations entre les deux rives du sahara», Revue Mediterannée, no. 3-4, pp. 31-40

PORTES, Alejandro y Jòzsef Böröcz (1987), «Contemporary immigration: Theoretical Perspectives on its Determinants and Modes of Incorporation», International Migration Review, 23(3), pp. 606-30. 
REFAss, Mohamed Azeddine (1999), «Les Transferts des Ressortisants Marocains à l'Etranger», M. Berriane y H. Popp (eds.), Migrations Internationales entre le Maghreb et l'Europe, Université Mohammed v, Rabat, 97-105.

RENIERS, Georges (1999), «On the History and Selectivity of Turkish and Moroccan Migration to Belgium», International Migration, 37(4), pp. 679-713.

RUHS, M. (2005), The potential of temporary migration programmes in future international migration policy, GCIM, Ginebra.

SALIH, Ruba (2001), «Moroccan Migrant Women: Transnationalism, Nation-States and Gender», Journal of Ethnic and Migration Studies, 27(4), pp. 655-671.

schoorl, Jeanette, Liesbeth Heering, Ingrid Esveldt, George Groenewold, Rob van der Erf, Alinda Bosch, Helga de Valk y Bart de Bruijn (2000), Push and Pull Factors of International Migration: A Comparative Report, Eurostat, Luxembourg.

SELL, Ralph R. (1988), «Egyptian International Labor Migration and Social Processes: Toward Regional Integration», International Migration Review, Vol. 22(3), pp. 87-108.

SKELDON, Ronald (1997), Migration and Development: A Global Perspective, Longman, Essex.

TETO, Abdelkader (2001), Contribution des Transferts à la Solidarité Sociale et Familiale, à la Consolidation des Filets de Sécurités et de Protection contre la Pauvreté: Cas du Maroc, ERf Poverty Workshop, Sana'a, Yemen.

Zelinsky, W. (1971), The Hypothesis of the Mobility Transition, Geographical Review, 61(2), pp. 219-49.

zoHry, Ayman y Barbara Harrell-Bond (2003), Contemporary Egyptian Migration: An Overview of Voluntary and Forced Migration, DRC on Migration, Globalisation and Poverty, Brighton. 